This is the accepted version of the article by $\mathrm{C}$. Vindrola-Padros and $\mathrm{E}$. Brage, What is not, but might be: The disnarrated in parents' stories of their child's cancer treatment, Social Science and Medicine, 2017; 193:16-22, https://doi.org/10.1016/j.socscimed.2017.09.048.

\title{
What is not, but might be: The disnarrated in parents' stories of their child's cancer treatment
}

\section{Cecilia Vindrola-Padros ${ }^{1}$ and Eugenia Brage ${ }^{2}$}

\author{
${ }^{1}$ Department of Applied Health Research, University College London, UK \\ ${ }^{2}$ Facultad de Filosofía y Letras, Universidad de Buenos Aires, Argentina. Consejo Nacional de \\ Investigaciones Científicas y Técnicas -CONICET-
}

\begin{abstract}
The study of illness narratives is based on the premise that stories are told for a reason and storytellers make narrative decisions on what to include and leave out of a story, the style of narration, the place where the story is told and the audience. Through this narrative work, they situate themselves in particular ways and make sense of the illness and the world around them. In this article, we explore the disnarrated, a style of narration that features events that do not happen, but are nonetheless referred to in the story. The aim of the article is to illustrate the additional layers of meaning that can be uncovered from illness stories when attention is paid to what did not happen, but, yet, is still part of the story. We draw from a qualitative study carried out with 17 parents whose children were diagnosed with cancer and were receiving medical care in Argentina. We carried out narrative interviews with the parents and participant-observation in hospital areas and the hotels where they resided during treatment. The analysis of the interview transcripts was carried out using a holistic understanding of the narratives and focusing on the
\end{abstract}


identification of themes that appeared disnarrated. The fieldnotes from the observations were used to contextualize the narrative analysis. The disnarrated, in its many manifestations, produced a layer of analysis of parents' stories of treatment patterned by parents' desires, hopes and fears. The disnarrated was used by parents to discuss alternative care trajectories and express fears regarding what the future would bring for the child and family. The disnarrated is a useful analytical tool for examining illness stories as it points to storytellers' views of what is acceptable or desirable in their world and their hopes and preferences for alternative realities.

Keywords: Argentina, illness narratives; disnarrated; narrative analysis; childhood cancer; parenting

\section{Introduction}

Narrative research is based on the premise that human experience is shared, storied and maintains recognizable narrative patterns (Gubrium and Holstein, 2009; Sandelowski, 1991). The act of storytelling follows culturally available configurations that act as guidelines but can also be modified by individuals in the creation of narratives (Frank, 1995; Mattingly et al., 2002: Rapport and Overing, 2000). There is also a degree of intentionality behind narrative construction (Garro and Mattingly, 2000). As Holstein and Gubrium (2012) have argued, stories are told for a reason. Storytellers make narrative decisions on what to include and leave out of a story, the style of narration, the place where the story is told and the audience (Harvey et al., 2000). Through this narrative work, they situate themselves in particular ways and make sense of the world around them (Ewick and Silbey, 1995). Narratives can therefore act as a window into socio-culturally sanctioned norms as well as individual desires and expectations (Shuman, 2012).

There are events in life such as the diagnosis and experience of living with a serious illness that can evoke particular narrative types (Frank, 1995; Kleinman, 1980). In the context of 
disease, the flexibility of narrative creation allows the ill person and those who care for them to cope with the biographical disruption that might have been produced by the discovery of a disease, make sense of their lives as "sufferers" or "carers" and (re)construct their plans for the future (Kleinman, 1988; Del-Vecchio Good et al., 1994; Little et al., 1998). From an analytical point of view, illness narratives are a useful tool to uncover the negotiation of biomedical discourses of disease and treatment, as individuals take biomedical conceptual templates and rework them in daily life (Hunt, 2000; Mathieson and Stam, 1995). Illness stories can also provide insight into the affective strategies used by the narrator to generate an emotional response in the audience (Garro and Mattingly, 2000).

In a previous article, we presented a proposal for analyzing illness narratives based on three main components: the narrated, the non-narrated and the disnarrated (Vindrola-Padros and Johnson, 2014). This proposal emerged out of our desire to expand our analysis of stories beyond what was found explicitly in the text. This approach for the analysis of narratives is based on examining the content of the story and identifying the characters, scenes, and plots. However, it also requires the reading of stories in relation to the elements that are missing, silenced or purposely deleted (the non-narrated). A third dimension is the disnarrated, the main focus of this article. The disnarrated refers to "all the events that do not happen though they could have and are nonetheless referred to (in a negative or hypothetical mode) by the narrative text" (Prince 1992:30; emphasis in the original).

In this previous work, we subjected the same transcripts to all three analytical approaches (the narrated, the non-narrated and the disnarrated) and found that the disnarrated allowed our study participants to position themselves differently, in hypothetical form or alternative reality, thus providing insight into an additional layer of their feelings, identity, needs and desires 
(Vindrola-Padros and Johnson, 2014). We would not have been able to capture this layer if we had only focused our analysis on the narration of the story as it happened. This previous work on the disnarrated presented it as a more or less homogenous narrative strategy where events that did not happen were included in the story (Vindrola-Padros and Johnson, 2014). In this article, however, we hope to carry out further analytical work to identify the main principles of the disnarrated and the different ways in which it might manifest itself in illness narratives. We draw from the stories of parents whose children were diagnosed with cancer in Argentina to illustrate the additional layers of meaning that can be uncovered from their stories when attention is paid to what did not happen, but, yet, is still part of the story.

\subsection{The disnarrated as an analytical tool}

The disnarrated includes styles of narration where the narrator might reflect on something that did not happen (I wonder what would have happened if...), consider potential outcomes of a decision (If I do this, then X might happen, but if I do that, the Y might happen), or tell the audience what did not happen (he did not visit her as much as he said he would). A critical element of the disnarrated is tellability, the fact that "a narrative is worth telling because it could have been otherwise and usually is otherwise" (Kartunnen, 2008: 419; emphasis in the original). In other words, the main question that emerges out of the analysis of the disnarrated is, if the event did not happen, then why is it part of the story? This question tries to tackle the intentionality behind narrative work and the ways in which stories can be used "to do something".

According to Prince (1992), the disnarrated makes the reader consider alternative realities, possibilities that are never materialized, but have the potential to materialize. Simple 
negations (i.e. this did not happen) do not form part of the disnarrated; the disnarrated must touch on "what is not but might be" (Prince, 1992:35). It is the product of narrative logic where an alternative option is part of every narrative function, that is, it is based on the premise that when a narrative choice is made, there are potential options that are cast aside (Bremond 1973). The disnarrated concerns the options that are not chosen (Bremond, 1973; Prince, 1992).

The inclusion of these unrealized options in the narrative is what makes the disnarrated such a useful analytical tool. By alluding to disnarrated events, the narrator expresses a sense of what is possible or acceptable in the world of the characters in the story, highlighting social norms or conventions (Kartunnen, 2008). The disnarrated can be used to create emotional responses in the reader such as suspense, surprise, hope, and fear by describing an advance of what could happen (but does not) (Lindholm, 2003; Prince, 1992). It can also be used to deceive the reader by making them believe something will happen or mislead them into reaching conclusions that are then shattered when the story unfolds (Baker, 1995). The disnarrated can also be used by the narrator to reconsider past actions, wondering what would have happened if things had taken a different course of events, sometimes expressing regret with regards to decisions that were not made (Vindrola-Padros and Johnson, 2014). The disnarrated can occupy all three temporal dimensions, appearing as alternatives in the past, hypothetical situations in the present, and possibilities in the future (Baker, 1995; Karttunen, 2008; Willem, 2012). In the following sections of the article, we will describe the design and methods used in the study and present the manifestations of the disnarrated in these three temporal dimensions.

\section{Methods}


The second author, an anthropologist with ethnographic research experience in healthcare contexts, carried out the study in Buenos Aires, Argentina from May 2013 to November 2015. The study used in-depth interviews with families who travelled to Buenos Aires to obtain oncology treatment for their children and hospital staff members who cared for the children. The study also used participant observation in a children's hospital and hotels where the families stayed during treatment. In this article, we present data from the interviews and observations with parents.

\subsection{Research context}

Approximately $80 \%$ of childhood cancer cases in Argentina are treated in the public health system free of charge (Moreno et al., 2009). The childhood cancer survival rate at five years after diagnosis in Argentina is lower than in other countries such as the US (61\% in Argentina compared to $83 \%$ in the US) (Abriata, et al., 2010; Siegel et al., 2015). This lower survival rate has been attributed to delays in diagnosis produced by the unequal distribution of specialized centers for cancer treatment, lack of training of primary care professionals on the identification of early symptoms of cancer and lack of diagnostic equipment (Casak et al., 1997; Chantada et al., 1999; INC, 2015).

Despite efforts to implement a decentralized health system, about half of all childhood cancer cases are treated in five public hospitals in Buenos Aires (Brage, 2013). This centralized distribution of specialized cancer services leads to the migration of $46 \%$ of the children from different parts of the country to Buenos Aires at some point in the treatment (Moreno et al., 2013). This process has been locally referred to as assistance migration (Moreno et al., 2013) and constitutes a care strategy developed by the health system and often used by families (Vindrola- 
Padros, 2012; Brage, 2015). Families normally relocate to Buenos Aires during the entire duration of treatment and continue to travel to the capital for monitoring after treatment has been completed (Vindrola-Padros and Brage, 2017).

\subsection{Data collection}

The following methods of data collection were used:

1) Narrative interviews with mothers and fathers of children with cancer who were undergoing treatment were carried out in the hospital (mainly in inpatient wards) and in the hotels. One parent from each family was interviewed. The interviews were mainly unstructured and only included a few phrases designed to prompt the construction of the narrative. The interview began with a general prompt to elicit the narration of parents' stories: "Please tell me how everything started". The interviews lasted approximately 90 minutes and were audio recorded.

2) Participant observation was carried out in specific areas of the hospital such as the main entrance hall, the oncology day unit, inpatient wards, and waiting rooms as well as in the hotels where the families lived while the children obtained treatment in Buenos Aires. The observations were recorded in the form of unstructured field notes.

\subsection{Recruitment and sampling}

The sample was defined according to the place of origin of the families. Potential participants were identified by the clinical leads of the wards. The clinician first asked the parents if they could be approached by the researcher. If the parents agreed, the researcher then approached them with written information sheets describing the study aims, what their participation would 
entail, the benefits and potential risks of participation, and the researcher's contact information. The information sheets also informed potential participants that their participation was voluntary, they could withdraw from the study at any time, and anything they said would remain confidential. They were also instructed that any contributions they made to the study would not render them identifiable. The potential participants then had time to ask the researcher questions about the study. If they agreed to take part in the study, they were asked to sign a consent form.

The inclusion criteria were: 1) parents and /or primary caregivers of children from the provinces of the north-west and north-east of Argentina, 2) parents whose children were receiving oncology treatment in the children's hospital where the study took place. Thirteen mothers and four fathers agreed to take part in the study. Nobody refused to take part in the study. Ten interviews were carried out in the hospital's inpatient wards and seven interviews took place in two hotels. The characteristics of the research participants are summarized in Table 1.

INSERT TABLE 1 HERE

The protocol, information sheets, consent forms, and data collection materials were reviewed and approved by the Ethics Committee of the hospital where the study took place. The study followed national and international ethical recommendations on the use of qualitative methods in health services research (Richards and Swartz, 2002; Silverman, 2013; Whiteford and Trotter, 2008).

\subsection{Data Analysis}


The 17 interviews were transcribed verbatim and anonymized. The interview transcripts and field notes were imported into Atlas.ti, qualitative data analysis software. The principal researcher first familiarized herself with the data, carrying out a holistic reading of each narrative. During this holistic understanding of the narratives, the researcher followed Riessman's (1993) components of narrative analysis (attending, telling, transcribing, analyzing and reading). Special attention was paid to the telling of the narratives (what is included in the story and how it is told) and the context where the narratives take place and are co-constructed (attending) (Riessman, 1993).

This holistic reading was combined with detailed line by line reading and coding. This coding focused on identifying the disnarrated in the style of narration (based on the principles proposed by Prince (1992)) and was cross-checked by both authors. Disnarrated fragments of the interviews were extracted, but short vignettes summarizing the main topics of the narrative, characteristics of the narrator (i.e. age, gender, family composition, characteristics of the ill child, diagnosis and prognosis of the child, place of origin and types of journeys to Buenos Aires), and context of narrative construction (obtained through field notes) were developed and paired with each fragment (in the form of memos) to avoid the decontextualization of the quotes.

The disnarrated fragments were analyzed in detail and codes were grouped into themes (Braun and Clarke, 2006). These themes were then explored in relation to the contextual information gathered through participant observation. In this process of contextualizing the themes, the authors applied the concept of tellability. Tellability is based on examining what makes a story tellable, by whom, to whom and in what circumstances (Labov, 1972; Ochs and Capps, 2001). As Shuman has argued, "what makes a story tellable is always a matter of both the content of the story and the context of the storytelling occasion" (2012: 129). Our analysis of the 
inclusion of disnarrated events in parents' stories was framed under this concept of tellability in the sense that we asked why, if these events did not happen, were they included in the story. Why is the story worth narrating in this way?

\section{Results}

Our analysis of the disnarrated in parents' stories of their child's cancer treatment led to the identification of three main styles of disnarration based on the temporal context the narrator referred to. In the following section, we present an overview of the three styles and the main topics they covered.

\subsection{The disnarrated past: Misdiagnosis and alternative clinical pathways}

In cases where the disnarrated appeared in the past, it was used by the narrators to describe the diagnosis or early treatment stages. Previous research on cancer narratives has highlighted the important and disruptive role played by a cancer diagnosis in the stories of children and their family members (Goldbeck, 2001; Santacroce, 2002; Young et al., 2002). A cancer diagnosis has been said to produce a "fracturing of reality" (Clarke-Steffen, 1993) or biographical disruption (Bury, 1982; Williams, 1984) in the lives of both children and parents. In the case of the parents who shared their stories with us, their reflections of the past underlined the salient role played by the diagnosis and parents could vividly recall when they first heard their child had cancer. However, their stories did not reflect a straightforward journey to obtain a diagnosis. In fact, the "correct" diagnosis was often something parents had to "fight for". The disnarrated was used to reveal what Prince has referred to as "the choices not made, roads not taken, possibilities not actualized, goals not reached" (1992: 36), in this process of obtaining a diagnosis and securing 
treatment, but also uncovered the mistakes that were avoided and decisions that were questioned and corrected. In some instances, the disnarrated was used to corroborate that parents had 'done the right thing' and were 'good parents', a process Baruch (1981) has referred to as accomplishing moral adequacy.

Parents pointed out what could have happened if the health system had "worked properly", if they had not intervened, if they had not sought advice from another doctor. An example can be found in the quote below from Rosa, whose son, Pedro ( 3 years old), had been diagnosed with a tumor of the central nervous system in the province of Misiones.

"We came on our own because the neurologist said that if she referred us, we were going to end up in Posadas and they would surely operate on him there. So, she said, 'go on your own' [to Buenos Aires] and that is what we did and we came through the emergency department and came alone" (emphasis on the disnarrated).

Juan did not have the surgery and the family did not travel to Posadas, yet these possibilities are still part of Rosa's story. Rosa uses the possibility of potential surgery to indicate that this potential treatment option (surgery) in this specific place (Posadas) was not something she wanted for her child. Another example is the quote from Laura's mom, Clara, who struggled to get a leukemia diagnosis for her 3-year-old daughter.

"What they told me was that she needed to have an urgent lumbar puncture, I was going to let them do it there [Corrientes], but there were problems with our 
insurance, the hospital would not accept it. So, I made the decision to bring her here [Buenos Aires]" (emphasis on the disnarrated).

Laura did not have the procedure in Corrientes, but Clara mentions it to explain the problems they experienced with her insurance. In the case of Rosa's and Clara's quotes, the disnarrated functions to highlight additional dimensions of past events in the children's treatment trajectories, events that could have happened, but didn't. In both cases, the disnarrated events function to confirm that the parents' decisions were "correct", that is, they led to avoiding surgery in Juan's case and bypassing insurance problems in Laura's case. However, the disnarrated past was also used to rethink past decisions in negative light. Sara was very upset during one part of our interview when she remembered all of the time she had to wait to get a diagnosis for her child, heavily influencing his chance for a successful treatment. At one point she said, "It makes me so angry, such impotence, we could have avoided all that pain" (emphasis on the disnarrated). In this case, the disnarrated evidently exposes Sara's regrets.

\subsection{The disnarrated present: the practicalities of daily life}

When appearing in the present tense, the disnarrated reflected more of the day to day hypothetical situations available to the children and their families. This could be due to the fact that the interviews were carried out while the children and their parents were in Buenos Aires to obtain treatment and not after treatment was completed. Marta's mom reflected on her family's current living arrangements during the interview by saying, "My husband is in Rosario, he got a job there. This way he is closer to us [they are originally from Misiones], because what would we do here in Buenos Aires without a job?" (emphasis on the disnarrated). Marta's mom presents 
another potential option for the family (all of them migrating to Buenos Aires, but without secure income), but quickly discounts this option by arguing that the sensible option was for her husband to live in Rosario (where he had a job) while Marta and her mom move to Buenos Aires to obtain treatment.

This use of the disnarrated allows us to gain insight into the narrator's expectations of what should happen based on their interpretation of social conventions and norms (Karttunen, 2008: 420). According to Karttunen, "by pointing to unrealized lines of development or rejecting a social or literary norm or convention, the disnarrated makes these norms and conventions visible" (2008: 420). The interview with Marta's mom alluded to her views of family life and the fact that it is better for family members to stay close together so they can help each other cope with the child's treatment. She uses the disnarrated to justify the reason why all family members were not living in Buenos Aires during the child's treatment. The family were closer, but they could not be as close as they wanted to (or should have been). However, this was justified because the husband needed to work to provide the family with stable income while they were in Buenos Aires.

Another hypothetical scenario was described by Luisa's mom,

"This is a struggle for us. We want to leave. We are thinking about her [refers to her daughter], she does not want to be here [Buenos Aires]. The hotel is not like her house, with everything confined. If we were home, then she would be free. The houses are not all stuck together like here where you wake up, get out and it feels like the building is going to fall on top of you" (emphasis on the disnarrated). 
This use of the disnarrated, points to an alternative way of living through her child's treatment that Luisa's mom knows cannot be realized as she knows her daughter can only receive treatment in Buenos Aires. Why does she mention it then? By including this option in the story, Luisa's mom is shining light on her views of how people should live (with open spaces), but also on the living situation she had in her place of origin. In a way, her quote is flavored with a sense of homesickness and the desire to return home. Feelings of loss are common in cancer narratives and they manifest themselves in multiple ways (Woodgate, 2006; Woodgate and Degner, 2003). The loss of normality, daily routines, and "connectedness to their world" (Woodgate, 2006: 17) often creates emotional distress in children with cancer and their families. In the cases of the families who shared their stories with us, feelings of loss were also related to their need to migrate to a new and strange city to obtain medical treatment. The disnarrated was often used as a tool to express these feelings of not wanting to be in Buenos Aires and wanting to be somewhere else (home).

\subsection{The disnarrated future: fears and uncertainty}

The disnarrated future is more difficult to analyze as we do not know what will happen and cannot identify "the roads not taken" (Prince, 1992: 36). Baker (1995) grapples with this issue in the field of literary analysis and proposes to look at the disnarrated future by exploring "the critical discrepancy between what was asserted to be certain to happen and what actually happened" (Baker, 1995: 276). In the case of our narratives, which are constructed through the interview process, we are not able to capture what actually happened as our interviews were conducted during one specific period of the parents' trajectory. However, we could still get a 
glimpse of the disnarrated future by focusing on the events and situations parents selected as potential alternatives for their families' future. In other words, future scenarios could have included many different topics, scenes, and characters and could have addressed a wide range of potential outcomes, however, parents chose to include and narrate very specific future scenarios in their narratives. Why did they include these and why did they present them this way?

For most of the parents who participated in the interviews, the future was marked by the completion of treatment and the return to their homes and families. Even though the potential to go back was narrated with hope and happiness, most of their reflections of the future focused on the vague knowledge they had with regards to the level of care their children would need after treatment and the fear that they would relapse. When thinking about the fact that Ruben was approaching the end of this treatment, his mother said, "I will not stop being afraid, there is always a risk, what if it [the cancer] comes back?" (emphasis on the disnarrated). Fear was also expressed in relation to the side-effects of the treatment. Daniel's mother explained the potential health problems her son could encounter after treatment:

"the chemos are very invasive and the radiation is aggressive. He could end up losing his eyesight and have thyroid problems, these are rays that could hurt him" (emphasis on the disnarrated).

The parents also reflected on the type of care their children would receive after they finished treatment and returned to their place of origin. Local care was rarely portrayed positively and it represented a noticeable source of anxiety for parents. Alicia's mother reflected on the next steps of her daughter's treatment by saying: 
"If I have to return to Corrientes [place of origin] for her follow-up care, I won't be fine with this. I don't care if I have to pay, I told the doctor, I will not return" (emphasis on the disnarrated).

Celina's mother had a similar opinion, "if we go back, I will be terrified of taking her to the pediatrician there [place of origin], I do not trust him" (emphasis on the disnarrated). This distrust was produced by previous negative experiences of care in the place of origin and the belief that healthcare professionals in Buenos Aires were better.

Uncertainty is a common component of cancer narratives (Cohen, 1995; Comaroff and Maguire, 1981; Humphrey et al., 1996; Neville, 1998) and varies in relation to the stage of the cancer trajectory (Woodgate and Degner, 2002). Even when the child has finished treatment and eventually stays in remission, the threat of the reappearance of the cancer remains (Woodgate, 2006). However, as Woodgate and Degner (2002) have argued, uncertainty is not always seen in negative light by parents, as not knowing can be reassuring and feelings of certainty do not always put children and their parents at ease. Through the construction of their child's illness narratives, parents work through these uncertainties and, in the case of the quotes presented above, use the disnarrated future as a way to anticipate potential situations and think through the ways in which they could react to them.

\section{Conclusion}

In the face of cancer, its treatment and the disruptions it generates to daily life, narratives can help make sense of the disease, treatment and life itself (Mathieson and Stam, 1995). The process 
of working through a disease and medical treatment has tangible consequences on the construction of the ill person's identity as well as the identities of those around them (Woodgate, 2006). This is the case of parents whose children are diagnosed with cancer and the continuous biographical work they do to make sense of events (Young et al., 2002).

In this article, we have proposed an analysis of illness stories by paying attention to the disnarrated. By focusing on the disnarrated (on the potential circumstances in parents' lives that could have happened, but did not, yet were still part of the story) we were able to get a glimpse of their way of conceiving the events and situations they encountered and were to encounter in their child's treatment. The disnarrated past brought out alternative ways in which their children could have been cared for, mainly pointing to their desire to streamline diagnosis and ensure treatment started sooner. The disnarrated present focused on the ways in which daily activities could play out if the families made different choices, for instance, if they didn't have employment during the child's treatment or if they secured better living arrangements in Buenos Aires. It was a useful tool for examining their desires and preferences during treatment as well as their views on family life.

The disnarrated future surfaced parents' uncertainty with regards to their child's treatment and health and was framed by a haunting question: "what if the cancer comes back?". Parents expressed a desire to have additional information on the care their children would require after treatment and what follow-up care in their place of origin would entail. Some parents expressed discontent in having to obtain follow-up care in their local hospitals after leaving Buenos Aires. The negative experiences encountered during their child's diagnosis and early stages of treatment (which we identified in the disnarrated past) influenced their perceptions of local care, often representing local doctors and facilities in negative light. The disnarrated, in its 
many manifestations, produced a layer of analysis of parents' stories of treatment patterned by parents' desires, hopes and fears. It became a window into their reflections of the past, needs in the present, and desires for the future.

This new insight into their experiences could help shed light on the changes that need to be made at the level of public policies and healthcare practices to address the needs of children with cancer and their family members. The conversations with parents discussed in this article clearly point to gaps in the healthcare system, which are manifested by the problems parents faced while trying to obtain a diagnosis and secure medical treatment for their children. The disnarrated present pointed to the wide range of social and financial needs (i.e. relocation, loss of employment, travel expenses) parents needed to address while caring for their ill child. Many of these needs were not recognized by existing health programs and sources of support such as charities and non-governmental organizations. The disnarrated future highlighted their need for more support and information after their child has finished treatment.

The disnarrated is not a straightforward style to study and its identification, especially in future tense, can be problematic. It is important to pay close attention to Prince's (1992) main principles of the disnarrated, but bear in mind that adaptations might need to be made to analyze text that has emerged out of natural conversations, such as interviews. When examining disnarrated fragments of interviews, we should not lose sight of the rest of narrative, the context of its construction, and the intended audience (Koven, 2012). In the case of narratives emerging out the interview encounter, we need to consider the fact that the narratives will be coconstructed in this process and through the interaction with the interviewer (Cashman, 2012). Prompts used by the interviewer could be contributing to the use of disnarrated styles. Future research could apply conversational analysis techniques to explore how the interviewer and 
interviewee (co)construct the disnarrated in interview encounters (Baruch, 1981; Silverman, 2006:112).

The performative nature of interviews where the interviewees position and reposition themselves in particular ways throughout the interview process (Baruch, 1981; Riessman,, 2008) should be a central element of our analysis of the disnarrated. The use of the disnarrated in this performance is one of the most useful aspects of this concept, as the disnarrated is a narrative style used to create particular effects in the story and responses from the audience (Lindholm, 2003; Prince, 1992). In other words, the disnarrated fragments in interviews are used to 'do something'. The purpose of applying the concept of the disnarrated to our analysis of illness stories is to unpack what this something is. Prince's (1992) concept of tellability (where we ask if this did not happen, why is it part of the story?) can represent a step in this direction. The answer to this question will partially lie in the interviewees' desires to present their story and themselves in a particular way, in the case of our study, as parents struggling to obtain the best available care for their children, despite evident deficiencies in the healthcare system.

Ethnographic research in this geographic context has described the strong role played by mothers throughout their child's cancer treatment and their portrayal of this maternal role as that of someone who would do anything to obtain the best care for their child (Vindrola-Padros, 2011). The disnarrated could be used to further highlight this accepted notion of motherhood.

The disnarrated should also be interpreted as a dynamic and iterative concept in the sense that narratives are not final (Mathieson and Stam, 1995), and therefore, disnarrated events (and the meanings associated with them) are bound to suffer transformations through time. Additional work needs to be done to refine our analysis of the disnarrated in illness stories, highlighting other principles, components and styles. Furthermore, analyses of the disnarrated should be 
carried out in longitudinal studies to explore how perceptions of what can (and should) happen can change throughout illness trajectories. 


\section{References}

Abriata, M.G., Moreno, F., 2010. Cáncer en la población de menores de 15 años en Argentina. Rev Argent Salud Pública 1(3), 42-5.

Baker, M., 1995. The “disnarrated” in Les Cent nouvelles nouvelles. Orhis Literarum 50, $272-$ 277.

Baruch, G., 1981. Moral tales: Parents' stories of encounters with the health professions. Sociology of Health and Illness 3(3), 275-295.

Brage, E. 2013. Problemas asociados a tratar niños con cáncer durante la etapa del final de la vida en casos de residencia alejada de las instituciones tratantes. VIII Congreso Nacional de Medicina y Cuidados Paliativos, Asociación de Medicina y Cuidados Paliativos. Mar del Plata, Argentina.

Brage, E. 2015. Entre la incertidumbre y el desarraigo: Una aproximación antropológica a la migración para tratamientos por cáncer infantil. Reunión de Antropología del Mercosur, Montevideo, Uruguay.

Braun, V., Clarke, V. 2006. Using thematic analysis in psychology. Qualitative Research in Psychology 3(2), 77-101.

Bremond, C., 1973. Logique du Recit. Seuil, Paris. 
Bury, M., 1982. Chronic illness as biographical disruption. Sociology of Health and Illness 4, $167-182$.

Casak, S., Zubizarreta, P., Scopinaro, M., Gallo, G., Schwartzman, E., Sackman, M., 1997. Experiencia en el tratamiento del Tumor de Wilms. Revista de Cirugia Infantil, 1, 139-146.

Cashman, R. 2012. Situational context and interaction in a folklorist's ethnographic approach to storytelling, in: Holstein, J., Gubrium, J. (Eds.), Varieties of Narrative Analysis. SAGE, Los Angeles, CA, pp. 181-206.

Chantada, G., Fadino, A., Manzitti, J., Urrutia, L., Schvartzman, E., 1999. Late diagnosis of retinoblastoma in a developing country. Archives of Disease in Childhood, 80, 171-174.

Clarke-Steffen, L., 1993. A model of the family transition to living with childhood cancer. Cancer Practice 1, 285-292.

Cohen, M., 1995. The triggers of heightened parental uncertainty in chronic, life-threatening childhood illness. Qualitative Health Research 5(1), 63-77.

Comaroff, J., Maguire, P., 1981. Ambiguity and the search for meaning: childhood leukemia in the modern clinical context. Social Science and Medicine 15B, 115-123. 
Del Vecchio Good, M., Munakate, T., Kobayashi, Y., Mattingly, C., Good, B., 1994. Oncology and narrative time. Social Science and Medicine 38(6), 855- 862.

Ewick, P., Silbey, S., 1995. Subversive stories and hegemonic tales: Toward a sociology of narrative. Law and Society Review 29(2), 197-223.

Frank, A., 1995. The Wounded Storyteller: Body, Illness, and Ethics. University of Chicago Press, Chicago.

Garro, L., Mattingly, C., 2000. Narrative as construct and construction, in: Mattingly, C., Garro, L. (Eds.), Narrative and the Cultural Construction of Illness and Healing. University of California Press, Berkeley, pp. 1- 49.

Goldbeck, L., 2001. Parental coping with the diagnosis of the childhood cancer: Gender effects, dissimilarity within couples, and quality of life. Psycho-Oncology 10, 325-335.

Gubrium, J., Holstein, J., 2009. Analyzing Narrative Reality. SAGE, Los Angeles.

Harvey, M., Mishler, E., Koenen, K., Harney, P., 2000. In the aftermath of sexual abuse: Making and remaking meaning in narratives of trauma and recovery. Narrative Inquiry 10(2), 291-311.

Holstein, J., Gubrium, J., 2012. Introduction: Establishing a balance, in: Holstein, J., Gubrium, J. (Eds.), Varieties of Narrative Analysis. SAGE: Los Angeles, pp. 1-14. 
Humphrey, G., Skeel, J., Boon, C., 1996. Uncertainty: A conceptual model applied to parental stress associated with prognostic uncertainty in pediatric oncology. International Journal of Pediatric Oncology 3, 47-51.

Hunt, L., 2000. Strategic suffering: Illness narratives as social empowerment among Mexican cancer patients, in: Mattingly, C., Garro, L. (Eds.), Narrative and the Cultural Construction of Illness and Healing. University of California Press, Berkeley, pp. 88-107.

Instituto Nacional de Cancer (INC)., 2015.Cancer infantil.

http://www.msal.gov.ar/inc/index.php/acerca-del-cancer/cancer-infantil (accessed 27.02.2015).

Karttunen, L., 2008. A sociostylistic perspective on negatives and the disnarrated: Lahiri, Roy, Rushdie. Partial Answers: Journal of Literature and the History of Ideas 6(2), 419-441.

Kleinman, A., 1980. Patients and Healers in the Context of Culture: An Exploration of the Borderland between Anthropology, Medicine, and Psychiatry. University of California Press, Berkeley.

Kleinman A., 1988. The illness narratives: Suffering, healing and the human condition. Basic Books, New York.

Koven, M., 2012. Speaker roles in personal narratives, in: Holstein, J., Gubrium, J. (Eds.), Varieties of Narrative Analysis. SAGE, Los Angeles, pp. 151-180. 
Labov, W., 1972. Language in the Inner City. University of Pennsylvania Press, Philadelphia.

Lindholm, H., 2003. Perhaps she had not told him all the story: The disnarrated in James Joyce's Dubliners, in: Iftekharuddin F., Boyden J., Rohrberger M., Claudet J., editors. (Eds.), The postmodern short story: Forms and issues. Praeger, Westport. CT, pp. 207-219.

Little, M., Jordens, C., Paul, K., Montgomery, K., Philipson, B., 1998. Liminality: A major category of the experience of cancer illness. Social Science and Medicine 47(10), 1485-1494.

Mathieson, C., Starn, H., 1995. Renegotiating identity: Cancer narratives. Sociology of Health and Illness 17(3), 283-306.

Mattingly, C., Lawlor, M., Jacobs-Huey, L., 2002. Narrating September 11: Race, gender, and the play of cultural identities. American Anthropologist 104(3), 743-753.

Moreno, F., Schvartzman, E., Scopinaro, M., et al., 2009. Registro Oncopediátrico Hospitalario Argentino. Resultados 2000- 2008. ROHA, Buenos Aires, Argentina.

Moreno, F., Dussel, V., Abriata, G., Loria, D., Orellana, L., 2013. Registro Oncopediátrico Hospitalario Argentino (ROHA). Ministerio de Salud, Buenos Aires, Argentina.

Neville, K., 1998. The relationship among uncertainty, social support, and psychological distress in adolescents with cancer. Journal of Pediatric Oncology Nursing 15(1), 37-46. 
Ochs, E., Capps, L., 2001. Living Narrative: Creating Lives in Everyday Storytelling. Harvard University Press, Cambridge, MA.

Prince, G., 1992. Narrative as Theme: Studies in French Fiction. University of Nebraska Press, Lincoln.

Rapport, N., Overing, J., 2000. Social and Cultural Anthropology: The Key Concepts. Routledge, London.

Registro Oncopediátrico Hospitalario Argentino (ROHA)., 2012. Resultados 2000-2013. Instituto Nacional del Cáncer, Ministerio de Salud de la Nación, Buenos Aires, Argentina.

Richards, H. Schwartz, L., 2002. Ethics of qualitative research: are there special issues for health services research? Family Practice 19(2), 135-139.

Riessman, C.K., 1993. Narrative Analysis. SAGE, Newbury Park, California.

Riessman, C. K., 2008. Narrative Methods for the Human Sciences. SAGE, Thousand Oaks, CA.

Sandelowski, M., 1991. Telling stories: Narrative approaches in qualitative research. IMAGE: Journal of Nursing Scholarship 23(3), 161-166. 
Santacroce, S., 2002. Uncertainty, anxiety, and symptoms of posttraumatic stress in parents of children recently diagnosed with cancer. Journal of Pediatric Oncology Nursing 19, 104-111.

Shuman, A., 2012. Exploring narrative interaction in multiple contexts, in: Holstein, J., Gubrium, J. (Eds.), Varieties of Narrative Analysis. SAGE, Los Angeles, pp. 125-150.

Siegel, R. L., Miller, K. D., Jemal, A., 2015. Cancer statistics, 2015. CA: A Cancer Journal for Clinicians 65, 5-29.

Silverman, D., 2006. Interpreting Qualitative Data: Methods for Analyzing Talk, Text and Interaction. SAGE, London.

Silverman, D., 2013. Doing Qualitative Research: A Practical Handbook. SAGE, London.

Vindrola-Padros, C. 2011. Life and Death Journeys: Medical Travel, Cancer, and Children in Argentina. Doctoral dissertation, University of South Florida, Tampa, FL.

Vindrola-Padros, C. 2012. The everyday lives of children with cancer in Argentina: Going beyond the disease and treatment. Children and Society 26, 430-442.

Vindrola-Padros, C., Brage, E. 2017. Child medical travel in Argentina: Narratives of family separation and moving away from home, in: Ergler, C., Kearns, R., Witten, K. (Eds.), Children's Health and Wellbeing in Urban Environments, Routledge, New York, pp. 128-144. 
Vindrola-Padros, C., Johnson, G.A. 2014. The narrated, nonnarrated, and the disnarrated: Conceptual tools for analyzing narratives in health services research. Qualitative Health Research 24(11), 1603-1611.

Whiteford, L., Trotter, R.T.II, 2008. Ethics for Anthropological Research and Practice. Waveland Press, Long Grove, IL.

Willem, L., 2012. The story not told: Sex and marriage in Pardo Bazán's "Los cirineos" and "La argolla”. Hispania 95(4), 587-95.

Williams, G., 1984. The genesis of chronic illness: Narrative re-construction. Sociology of Health and Illness 6, 175.

Wilson, S., 2007. When you have children, you're obliged to live: motherhood, chronic illness and biographical disruption. Sociology of Health \& Illness 29, 610-626.

Woodgate, R., 2006. Life is never the same: Childhood cancer narratives. European Journal of Cancer Care 15, 8-18.

Woodgate, R., Degner, L., 2002. "Nothing is carved in stone!”: Uncertainty in children with cancer and their families. European Journal of Oncology Nursing 6(4), 191-202. 
Woodgate, R., Degner, L., 2003. A substantive theory of keeping the spirit alive: The spirit within children with cancer and their families. Journal of Pediatric Oncology Nursing 20(3), 103119.

Young, B., Dixon-Woods, M., Findlay, M., Heney. D., 2002. Parenting in a crisis:

conceptualising mothers of children with cancer. Social Science and Medicine 55, 1835-47. 